\title{
Honing Process of Hydraulic Cylinder Bore for Remanufacturing
}

\author{
Pin-pin Qin ${ }^{1, a}$, Chun-lan Yang ${ }^{2, b^{*}}$, Wei Huang ${ }^{3, c}$, \\ Gui-wei $\mathrm{Xu}^{4, \mathrm{~d}}$ and Chun-jian Liu ${ }^{5, \mathrm{e}}$ \\ 1,2,3,5 College of Mechanical Engineering, Guangxi University, Nanning, Guangxi, China \\ ${ }^{4}$ Remanufacturing Company, Guangxi Liu Gong Machinery Co., Ltd, Liuzhou, Guangxi, China \\ aqpinpin@gxu.edu.cn, b365496998@qq.com, 'buaahw@126.com, \\ d249887043@qq.com, ${ }^{e} 944960662 @ q q . c o m$ \\ * please mark the corresponding author with an asterisk
}

Keywords: Remanufacturing; Honing; Hydraulic Cylinder.

Abstract. Hydraulic cylinder is the core of construction machinery remanufacturing. Remanufacturing enterprises in China are eager for finding out feasible remanufacturing process for the used hydraulic cylinder, which main failure mode is scratch on the surface of hydraulic cylinder bore. Causes of failure mode and feasibility of honing process applied on of hydraulic cylinder bore remanufacturing are analyzed considering three factors: little machining allowance, overlapping curve and high surface quality. The honing process technology is presented, including selection of honing machine, honing oilstone, honing oil and process parameters of course honing, micro honing and polishing, and honing process for remanufacturing. A case of applying honing process on boom cylinder bore remanufacturing is given and proved to be feasible in practice.

\section{Introduction}

A large number of failure mode hydraulic cylinder is eliminated and abandoned in China. If they can be remanufactured, then remanufacturing will earn numerous benefits for the original equipment manufacturers (OEMs) [1-2]. Hydraulic cylinder is the core part for construction machinery remanufacture [3]. Because products are restored to a like-new condition, remanufacturing is characteristically distinct from repair, refurbishment, or reuse activities [4]. So the remanufacturing technology become the key in the process of remanufacturing. Our study contributes to the development of this stream of research. A remanufactured product is one that has gone through "the process of disassembling, cleaning, inspecting, repairing, replacing, and reassembling the components of apart or product to like-new condition" [5-6].

\section{Analysis of scratch failure mode for hydraulic cylinder bore}

Typical failure mode is internal leakage which caused by scratch on the cylinder bore [7]. The scratching cylinder bore will form more obvious scratch, which will scratch the sealing ring with raised edges, thus make the oil leakage from the high pressure areas to low pressure areas inside the hydraulic cylinder. Because the two cavities of hydraulic cylinder are interlinked, internal leakage will reduce the output power of the hydraulic cylinder. There are two primary causes of scratch. First, once hard impurities squeeze into the clearance between cylinder bore and piston with poor cleanliness, which will scratch the cylinder bore as the piston moving. Second, under the external impact the coaxial degree of piston and cylinder cannot be guaranteed within the setting range, which cause the piston rim and cylinder bore to bite into each other and lead to the " cylinder scoring" phenomenon. The failure mode of the cylinder scratch is shown in Figure 1. 


\section{Feasibility analysis of honing process for hydraulic cylinder remanufactured product}

Honing process is one of repairing size method. Honing is an abrasive machining process that can produce very exact results regarding geometry, form and surface quality of the honed work piece. It is mainly used as the final finishing operation for ready-made bores and has to meet high demands regarding process stability and repeatability [8]. Quality parameters for these bores are form and geometric accuracy as well as surface roughness and structure. All requirements can economically be met by using the honing process as the final finishing operation for readymade bores [9].

According to statistics made by remanufacturing company, the scratch depth of hydraulic cylinder bore is shallow, the range usually is between $0.05 \mathrm{~mm}$ and $0.3 \mathrm{~mm}$. For one hand, the honing process can remove little materials to achieve repairing purpose. The removable material is generally less than $0.1 \mathrm{~mm}$, the honing head that floats during the process without special equipment to cooperate. But for inner bore honing process, which requires at least $0.3 \mathrm{~mm}$ machining allowance and need special equipment to cooperate. Obviously inner hole honing process can not satisfy the requirements of cylinder bore repairing. On the other hand, honing can make overlapping curve on the surface of cylinder bore, which can eliminate the longitudinal wear scar and are advantageous to storage lubricating oil during the process, then improving lubricating efficiency and protecting cylinder and piston from dry friction. But for the inner bore honing process, which can leave spiral tube line or coaxial ring on the surface of the cylinder bore.

There are three steps for honing repairing technology: rough honing, fine honing and polishing. Rough honing can quickly remove surface damage, eliminate strain scratch and improve processing efficiency. Fine honing can repair the flat surface and refine honing cross-textured. Polishing is able to further improve the surface quality of cylinder bore, which can create a better matching accuracy with the re-matching piston. Honing can achieve high machining surface quality, few machining allowance and form overlapping curve for scratched cylinder bore. So the honing process for cylinder bore repairing is feasible in theory.

\section{Honing process technology}

\section{Honing equipment selection.}

Honing machine selection. According to remanufacturing company, the type of honing machine is HTB-3000SC made in America. The maximum stroke length is $3000 \mathrm{~mm}$ and maximum machining diameter is $380 \mathrm{~mm}$, which can fully satisfy the requirements of the cylinder bore. Technical parameters of HTB-3000SC honing machine is shown in table 1.

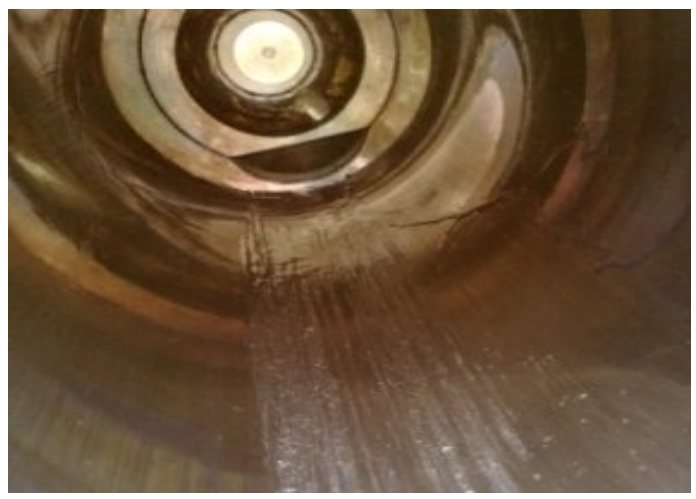

Figure 1. Scratch on the surface of hydraulic cylinder bore
Table 1. Parameters of honing machine

\begin{tabular}{|c|c|}
\hline Items & Parameters \\
\hline Machining diameter range & $25 \sim 400 \mathrm{~mm}$ \\
\hline $\begin{array}{c}\text { Maximum outside } \\
\text { diameter of work piece }\end{array}$ & $400 \mathrm{~mm}$ \\
\hline Spindle speed & $30 \sim 400 \mathrm{r} / \mathrm{min}$ \\
\hline Spindle motor power & $3.0 \mathrm{~kW}$ \\
\hline Stroke rate & $1 \sim 40 \mathrm{~m} / \mathrm{min}$ \\
\hline Adjustment time & $15 \sim 20 \mathrm{~min}$ \\
\hline Maximum stroke length & $3000 \mathrm{~mm}$ \\
\hline Maximum work piece weight & $6000 \mathrm{~kg}$ \\
\hline
\end{tabular}

Honing oilstone selection. According to the cylinder size and base material NO.45 steel, the technological parameters are determined by checking process manuals and several processing experiments. Coarse honing would use white corundum abrasive grain, size 150\#. Micro honing would use green silicon carbide grain, size 280\#. Four oilstones, each length is $100 \mathrm{~mm}$ and lip dimension is $12 \mathrm{~mm} \times 10 \mathrm{~mm}$. 
Honing fluid selection. According to the base material, 95\% kerosene $+5 \%$ sulfide minerals would be chosen as honing fluid and working temperature is $35^{\circ} \mathrm{C}-40^{\circ} \mathrm{C}$ by checking process manuals and several processing experiments.

Honing parameters. The main technological parameters of honing are overlapping curve crossing angle, spindle speed and stroke rate and honing pressure. Reference parameters are shown in table 2.

Since the failure mode situation of each used cylinder is not the same, it need to adjust the technological parameters according to the actual status. Increase of stroke speed and decrease of spindle speed can improve the honing efficiency, but too high stroke speed and too low spindle speed will do the opposite and cause larger surface roughness.

Table 2. Technological parameters of honing cylinder

\begin{tabular}{|c|c|c|c|c|}
\hline Process & $\begin{array}{c}\text { netted crossing } \\
\text { angle } \\
\left({ }^{\circ}\right)\end{array}$ & $\begin{array}{c}\text { Spindle speed } \\
(\mathbf{r} / \mathbf{m i n})\end{array}$ & $\begin{array}{c}\text { Stroke rate } \\
(\mathbf{m} / \mathbf{m i n})\end{array}$ & $\begin{array}{c}\text { Honing pressure } \\
(\mathbf{1 0} \mathbf{P a})\end{array}$ \\
\hline Rough honing & $45^{\circ}$ & 98 & 10 & 10 \\
\hline Fine honing & $30^{\circ}$ & 105 & 10 & 5 \\
\hline Polishing & - & 105 & 10 & 2 \\
\hline
\end{tabular}

Honing process for remanufacturing. Honing process for remanufacturing as the following:

Step 1: Initialization and clamping. Boot the machine and initialize, install the honing head and rough honing oilstone, fix hydraulic cylinder on the fixture, adjust appropriately height, lock work piece fastening chain. Set up stroke stop point and technological parameters.

Step 2: Rough honing. Turn on the short stroke switch. At the beginning, the stroke speed and honing pressure should be little, and increase gradually after the smooth running. Watch the pressure gauge and manually amend the cylinder taper. According to the scratch depth, several times honing are needed. First rough honing allowance should be controlled within $0.05 \mathrm{~mm}$, and then check the surface by using the flashlight. If scratch still exists, rough honing again, machining allowance is controlled within $0.3 \mathrm{~mm}$.

Step 3: Fine honing. After rough honing is finished, put on the fine honing oilstone, reset technological parameters according to requirements. The working time should be controlled within 2-3 minutes and the bore diameter should be measured again.

Step 4: Polishing. Cover special polishing cloth around fine honing oilstone, polishing time should be controlled within 3 4 minutes. When removed honing head out of bore, oilstone should be adjusted appropriately to avoid oilstone or guide frame scratching cylinder bore.

Step 5: Detection and removal of work piece. After the removal of the honing head, measure inner diameter of the cylinder bore by micrometer and then write down a record. Finally work piece are removed and placed in the specified location.

\section{Case}

Boom cylinder is an important part of engineering machinery, which is the final step to convert hydraulic power into concrete action. It plays a key role in the hydraulic transmission system, its performance directly determines the performance of the whole hydraulic transmission system and its reliability level.

Taking a certain type of loader boom cylinder as an example, the process of boom cylinder remanufacturing is formulated. Through the production practice and repeated repair test according to the honing process technology provided priority, the honing can completely eliminate the scratch and restore the original cylindrical degree $0.0255 \mathrm{~mm}$ and surface roughness $0.2 \mu \mathrm{m}$. As a result, the better quality of cylinder bore surface and machining accuracy are obtained, the honing operation is simple and convenient, and the production efficiency is also good. Remanufactured cylinder can match with the new size piston, so honing process realized the remanufacturing purpose. 


\section{Summary}

In this study, honing process of hydraulic cylinder bore for remanufacturing is provided. The selection of honing machine, honing stone and honing oil are given. Honing parameters of course honing, micro honing and polishing are proposed. Honing process for remanufacturing is also performed. Case shows that application of honing on hydraulic cylinder bore remanufacturing is feasible.

Like all research efforts, this study is not without limitations. The honing process in this paper can only be used on some certain type of scratch on the some certain place of the hydraulic cylinder bore. For different types of scratch on many different location, remanufactured hydraulic cylinder bore used our honing process showed uncertain roughness. We still don't know the detail relationship between different scratch and honing parameters. Despite these limitations, our study suggests important results for enterprises, application of honing on hydraulic cylinder bore remanufacturing in practice is proved to be correct. The research also shows that honing process of hydraulic cylinder bore for remanufacturing means lower remanufacturing costs. This would help to make great profits for large-scale hydraulic cylinder remanufacturing.

In the future, further experiments will be needed to determine other honing process parameters as the scratch location and depth are various.

\section{Acknowledgment}

The research was supported by Guangxi Natural Science Found, Project 2015GXNSFAA139280.

\section{References}

[1]Geyer, R., Van Wassenhove, and L. N., \& Atasu, A. ,The economics of remanufacturing under limited component durability and finite life cycles on remanufacturing profit, Management Science, 53 (2012) 88-100.

[2]Guide Jr, and V. D. R. Jr, Production planning and control for remanufacturing: Industry practice and research needs, Journal of Operations Management, 18 (2000) 467-468

[3]Serra Caner Bulmus, Stuart X. Zhu, and Ruud Teunter, Competition for cores in remanufacturing, European Journal of Operational Research, 233 (2014) 105-113.

[4]Benjamin T. Hazen, Robert E. Overstreet, L. Allison Jones-Farmer, Hubert S. Field. The role of ambiguity tolerance in consumer perception of remanufactured products Original Research Article, International Journal of Production Economics, 135 (2012) 781-790.

[5]Zhang, T., Chu, J., Wang, X., Liu, X., Cui, P. Development pattern and enhancing system of automotive components remanufacturing industry in China, Resources, Conservation, \& Recycling, 55 (6) 613-622.

[6]Cheng-Han $\mathrm{Wu}$, OEM product design in a price competition with remanufactured product, Omega, 41 (2013) 287-298.

[7]Wei Huang.Honing remanufacturing and experimental study on properties of Hydraulic cylinder[ A].The Fourth Annual Conference of the National Local Mechanical Engineering Society[C].Ganshu ,China, 11 (2014) 76-80.

[8]Schmitt, C. and D. Bähre, An Approach to the Calculation of Process Forces During the Precision Honing of Small Bores. Procedia CIRP Forty Sixth CIRP Conference on Manufacturing Systems, 7 (2013) 282-287. 
[9]Schmitt, C. and D. Bähre, Analysis of the Process Dynamics for the Precision Honing of Bores. Procedia CIRP Variety Management in Manufacturing Proceedings of the 47th CIRP Conference on Manufacturing Systems, 17 (2014) 692-697. 